\title{
ANALISIS KELAYAKAN FINANSIAL USAHA TANI KOPI ARABIKA (Coffea arabica) DI DESA SUNTENJAYA, KECAMATAN LEMBANG KABUPATEN BANDUNG BARAT
}

\author{
Oleh : \\ Akhmad Zakaria \\ Email : akhmadzakaria@unfari.ac.id \\ Fakultas Teknologi Pertanian, Universitas Al-Ghifari
}

\begin{abstract}
Abstrak
Desa Suntenjaya, Kecamatan Lembang merupakan salah satu daerah penghasil kopi arabika di Kabupaten Bandung Barat. Kendala dalam pengembangan usaha tani kopi arabika di Suntenjaya Lembang diantaranya adalah masih terbatasnya data dan informasi mengenai ketepatan kelayakan usaha yang dapat dijadikan acuan dalam pemanfaatan sumber daya tersebut secara optimal. Oleh karena itu, kajian kelayakan finansial usaha tani kopi arabika di Desa Suntenjaya, Kecamatan Lembang Kabupaten Bandung Barat ini perlu dilakukan dalam membantu untuk mengetahui kelayakan finansial usaha tani kopi arabika. Metode pengumpulan data dilakukan dengan cara kajian kepustakaan dan kajian lapangan. Data dan informasi yang dibutuhkan berupa data primer dan data sekunder. Pengumpulan data primer diperoleh melalui survei lapangan dan wawancara. Survei lapangan dilakukan melalui penyebaran kuesioner, yang meliputi kuesioner untuk data profil dan komponen biaya usaha tani kopi arabika di Desa Suntenjaya Lembang. Analisis yang digunakan dalam kajian ini adalah analisis finansial berdasarkan kriteria nilai keuntungan dan analisis finansial berdasarkan kriteria nilai NPV (Net Present V alue), B/C (Benefit) Cost) ratio, IRR (Internal Rate of Return), PBP (Payback Period) dan BEP (Break Even Point).
\end{abstract}

Kata kunci : Kopi arabika, Java preanger coffee, Kopi Jawa Barat, Analisis finansial Usaha tani kopi.

\begin{abstract}
Suntenjaya Village, Lembang district is one of the Arabica coffee producing areas in West Bandung regency. Which areas in the Manglayang Mountain, Suntenjaya has a great potential in producing the high quality arabica coffee. The obstacle in developing of Arabica coffee farming in Suntenjaya Lembang, is that lack of data and information about the feasibility of accuracy that can be referred in the utilization of these resources optimally. Therefore, the study of financial feasibility of Arabica coffee farming in the Suntenjaya Village, Lembang, West Bandung regency, is necessary conducted to determine the financial feasibility of Arabica coffee farming. The data compilation methods is done by literature and field study. The data and information that is needed are primary and secondary data. Primary data collecting is got by field survey and interviews. Field survey by spreading questionnaires, that involves the questionnaire for profile and cost component of arabica coffee farming in Suntenjaya Lembang. The analysis that is applied in this study is financial analysis based on the profit value criteria and financial analysis based on the NPV (Net Present Value), B/C (Benefit/ Cost) ratio, IRR (Internal Rate of Return), PBP (Payback Period) dan BEP (Break Even Point) value.
\end{abstract}

Keywords: Arabica coffee, Java preanger coffee, West java coffee, financial analysis of coffee farming.

Analisis Kelayakan Finansial Usaha Tani

AKHMAD ZAKARIA

Kopi Arabika (Coffea Arabica) di Desa

Suntenjaya, Kecamatan Lembang

Kabupaten Bandung Barat 


\section{PENDAHULUAN}

Kopi merupakan komoditas perkebunan yang memegang peranan penting dalam perekonomian Indonesia. Komposisi kepemilikan perkebunan kopi di Indonesia didominasi oleh Perkebunan Rakyat (PR) dengan porsi $96 \%$ dari total areal di Indonesia, dan yang $2 \%$ sisanya merupakan Perkebunan Besar Negara (PBN) serta 2\% merupakan Perkebunan Besar Swasta (PBS). Posisi tersebut menunjukkan bahwa peranan petani kopi dalam perekonomian nasional cukup signifikan. Hal ini juga berarti bahwa keberhasilan perkopian Indonesia secara langsung akan memperbaiki kesejahteraan petani. (Ditjen Perkebunan, 2013).

Lahan perkebunan di Jawa Barat saat ini, berdasarkan data BPS mencapai 494.900 hektar atau 13,28 persen dari luas total wilayah Provinsi Jawa Barat 3,7 juta hektar. Luas area perkebunan kopi di Jawa Barat membentang seluas $30.620 \mathrm{Ha}$, dengan $30.205 \mathrm{Ha}(98,64 \%)$ merupakan perkebunan kopi milik rakyat serta sekitar $415 \mathrm{Ha}(1,36 \%)$ adalah perkebunan milik perusahaan swasta. Perkebunan kopi tersebut tersebar di 18 Kabupaten/Kota se Jawa Barat. Potensi lahan pengembangan kopi arabika di Jawa Barat berdasarkan kajian Indikasi Geografis sekitar $600.000 \mathrm{Ha}$.

Desa Suntenjaya, Kecamatan Lembang merupakan salah satu daerah penghasil kopi arabika di Kabupaten Bandung Barat. Dengan daerah yang berada di pegunungan Manglayang Barat, Desa Suntenjaya mempunyai potensi yang besar dalam menghasilkan kopi arabika dengan kualitas terbaik. Petani kopi arabika di kawasan Suntenjaya Lembang tergabung dalam Asosiasi Petani Kopi Kabupaten Bandung Barat. Saat ini Petani melakukan usaha perkebunan kopi arabika di atas lahan milik Perum Perhutani KPH Bandung Utara, secara tumpangsari dengan tanaman hutan yaitu pinus.

Aspek keuntungan finansial merupakan suatu keharusan dalam pengusahaan suatu tanaman. Karena itu perlu diketahui apakah kondisi perkebunan kopi arabika di Desa Suntenjaya Lembang saat ini telah memberikan keuntungan yang sesuai bagi modal yang telah dikeluarkan petani. Untuk itu yang menjadi pertanyaan adalah bagaimanakah kelayakan finansial pengusahaan perkebunan kopi arabika di Desa Suntenjaya Lembang, Kabupaten Bandung Barat. Kendala dalam pengembangan usaha tani kopi arabika di Suntenjaya Lembang diantaranya adalah masih terbatasnya data dan informasi mengenai ketepatan kelayakan usaha yang dapat dijadikan acuan dalam pemanfaatan sumber daya tersebut secara optimal. Oleh karena itu, kajian kelayakan usaha tani kopi arabika di Suntenjaya Lembang Kabupaten Bandung Barat ini perlu dilakukan dalam membantu untuk mengetahui kelayakan finansial usaha tani di Desa Suntenjaya, Kecamatan Lembang, Kabupaten Bandung Barat.

Berdasarkan rumusan diatas maka tujuan penelitian ini adalah untuk menganalisis kelayakan finansial usaha tani perkebunan kopi rakyat di Desa Suntenjaya Kecamatan Lembang, Kabupaten Bandung Barat.

\section{METODE PENELITIAN}

Lokasi penelitian di wilayah administratif Kabupaten Bandung Barat Provinsi Jawa Barat. Lokasi Penelitian berada di Desa Suntenjaya, Kecamatan Lembang, Kabupaten Bandung Barat. Penelitian ini dilaksanakan dengan menggunakan data primer dan sekunder yaitu di Desa Suntenjaya, Kecamatan Lembang Kabupaten Bandung Barat..

Data dan informasi yang dibutuhkan berupa data primer dan data sekunder. Pengumpulan data primer diperoleh melalui survei lapangan dan wawancara. Survei lapangan dengan penyebaran kuesioner, yang meliputi: kuesioner untuk data profil dan komponen biaya usaha tani kopi arabika di Desa Suntenjaya Lembang 
Analisis data yang digunakan dalam kajian ini adalah analisis keuangan berdasarkan kriteria nilai keuntungan dan analisis finansial berdasarkan kriteria nilai NPV (Net Present Value), B/C (Benefit) Cost) ratio, IRR (Internal Rate of Return), PBP (Payback Period) dan BEP (Break Event Point).

\section{HASIL PENELITIAN}

\section{Analisis Usaha Tani Kopi Arabika Pendapatan}

Usaha tani kopi arabika mempunyai 1 kali panen dalam satu tahun. Dalam satu kali musim panen di Desa Suntenjaya rata-rata dihasilkan biji kopi siap panen (cherry/gelondongan) sebanyak $1500 \mathrm{Kg}-1700 \mathrm{Kg}$ dalam setiap 1 hektar lahan yang dikelola. Dengan produktivitas sebesar $1500 \mathrm{Kg}$ per hektar tergolong produktivitas sedang. Harga kopi arabika di tingkat petani untuk kopi arabika basah adalah Rp.6500-Rp.7000 per kg, sedangkan harga gabah kopi arabika kering adalah Rp.23000- Rp.24000 per $\mathrm{kg}$.

Berdasarkan data hasil produksi dan harga jual kopi arabika kering pada musim panen 2013-2016 diperoleh hasil panen kopi arabika gelondongan sebesar $1572.55 \mathrm{Kg}$, sehingga diperoleh gabah kering kopi arabika sebsesar $550.3925 \mathrm{Kg}$ dalam tiap hektar lahan yang dikelola. Berdasarkan hasil perhitungan, didapat penerimaan/ pendapatan bersih sebesar Rp.4.693.625 dalam setiap hektar lahan yang dikelola. Pendapatan petani per hektar lahan dapat dilihat pada tabel 1 berikut ini.

Tabel 1. Penerimaan petani per hektar lahan.

\begin{tabular}{|l|l|l|}
\hline \multicolumn{1}{|c|}{ PANEN } & \multicolumn{1}{|c|}{ CHERRY (Kg) } & \multicolumn{1}{c|}{ GABAH (Susut 65\%) (Kg) } \\
\hline Hasil Panen & 1572.5 & 550.375 \\
\hline Harga Jual / Kg & 6500 & 23000 \\
\hline Total Penerimaan & 10221250 & 12658625 \\
\hline Penerimaan Bersih (Rp.) & $\mathbf{2 2 5 6 2 5 0}$ & $\mathbf{4 6 9 3 6 2 5}$ \\
\hline
\end{tabular}

\section{Analisis Finansial Usaha Tani Kopi Arabika}

Secara umum aspek yang dikaji dalam studi kelayakan usaha meliputi aspek seperti teknis produksi, pemasaran dan keuangan. Analisis pendapatan usaha tani ini didasarkan atas luasan satu hektar dalam satu musim panen. Penerimaan usaha tani adalah selisih antara total produk yang dijual dengan harga yang berlaku di pasar. Penerimaan usaha tani kopi arabika terdiri atas penjualan kopi arabika yang dihasilkan dalam setiap kali panen dalam satu hektar (Umar, 1997).

Perhitungan kelayakan finansial usaha tani kopi arabika menggunakan lima kriteria investasi yaitu Net Present Value (NPV), Net Benefit Cost Ratio (Net B/C), Internal Rate of Return (IRR), Pay Back Period (PBP) dan Break Event Point (BEP). Terlebih dahulu dibahas mengenai biaya investasi dan biaya operasional termasuk biaya penyusutan.

Kegiatan awal seperti pembukaan lahan dan penanaman membutuhkan peralatan seperti cangkul, golok, arit, parang, gunting stek, obat pembasmi gulma/ herbisida, pupuk NPK, pupuk Urea untuk pemupukan awal dan bibit kopi arabika. Biaya investasi tanaman kopi pada tahun ke-1 digunakan untuk pembukaan lahan, pembuatan lubang, penanaman tanaman kopi. Sedangkan biaya Tahun Ke-2 dan ke 3 digunakan untuk perawatan tanaman, seperti pembersihan gulma, pemupukan dan pencegahan hama dan penyakit. Adapun untuk kegiatan penanganan hasil panen membutuhkan peralatan seperti bak kayu untuk pencucian dan terpal untuk penjemuran. Total biaya investasi awal untuk usaha tani kopi arabika di di Desa 
Suntenjaya Lembang adalah sebesar Rp.10.309.000. Rincian biaya investasi usaha tani kopi arabika di Desa
Suntenjaya, Lembang disajikan dalam tabel 2 berikut ini.

Tabel 2. Biaya investasi awal usaha tani kopi arabika.

\begin{tabular}{|c|c|}
\hline Biaya Investasi & HARGA \\
\hline Peralatan dan Bahan & (Rp.) \\
\hline \multicolumn{2}{|l|}{ A. Investasi Tahun Ke-0 } \\
\hline Bak Kayu & 505100 \\
\hline Terpal Penjemuran & 1594000 \\
\hline Cangkul & 129500 \\
\hline Golok & 195000 \\
\hline Arit & 97100 \\
\hline Parang & 97100 \\
\hline Gunting Stek & 135300 \\
\hline Handsprayer & 315700 \\
\hline Bibit Arabika & 1755900 \\
\hline \multicolumn{2}{|l|}{ Tenaga Kerja } \\
\hline Upah Penanaman Bibit & 603000 \\
\hline Pembersihan Lahan & 923600 \\
\hline Pemupukan & 504000 \\
\hline \multicolumn{2}{|l|}{ Biaya Pupuk } \\
\hline Pupuk NPK $(150 \mathrm{Kg})$ & 337500 \\
\hline Pupuk Urea (100 Kg) & 90000 \\
\hline \multicolumn{2}{|l|}{ Biaya Obat } \\
\hline Herbisida Round Up (4 Liter) & 220000 \\
\hline Total Investasi A & 7502800 \\
\hline \multicolumn{2}{|l|}{ B. Ivestasi tahun Ke-1 } \\
\hline \multicolumn{2}{|l|}{ Tenaga Kerja } \\
\hline Pemeliharaan, Pemupukan & 1000000 \\
\hline Pembersihan Lahan & 1000000 \\
\hline \multicolumn{2}{|l|}{ Biaya Pupuk } \\
\hline Pupuk NPK Subsidi & 337500 \\
\hline Pupuk Urea Subsidi & 90000 \\
\hline \multicolumn{2}{|l|}{ Biaya Obat } \\
\hline Herbisida Round Up & 165000 \\
\hline Total Investasi B & 2592500 \\
\hline Total Investasi Awal (A+B) & 10095300 \\
\hline
\end{tabular}

Biaya operasional usaha tani kopi arabika per tahun yaitu sebesar Rp.7.965.000 per hektar per tahun. Biaya operasional tersebut terdiri dari biaya tetap yaitu biaya penyusutan alat, biaya lahan dan biaya tidak tetap yaitu upah 
tenaga kerja, obat herbisida, pupuk NPK, pupuk urea. Rincian biaya operasional seperti tercantum pada Tabel 3.

Analisis perhitungan komponenkomponen biaya didapatkan total biaya pengeluaran yang terdiri dari biaya investasi awal dan biaya operasional untuk produksi kopi arabika adalah sebesar Rp.18.060.300,-.

Tabel 3. Biaya operasional per tahun usaha tani kopi arabika per hektar.

\begin{tabular}{|l|l|}
\hline Komponen Biaya & Biaya \\
\hline Biaya Tetap & \\
\hline Biaya Penyusutan alat & 250000 \\
\hline Biaya Lahan & 750000 \\
\hline Biaya Tak Tetap & \\
\hline Tenaga Kerja & \\
\hline Pemeliharaan, pemupukan & 1000000 \\
\hline Pembersihan Lahan & 1000000 \\
\hline Pemanenan & 2800000 \\
\hline Biaya Transportasi & 786250 \\
\hline Biaya Pengolahan & 786250 \\
\hline Biaya Pupuk & \\
\hline Pupuk NPK Subsidi & 337500 \\
\hline Pupuk Urea Subsidi & 90000 \\
\hline Biaya Obat & \\
\hline Herbisida Roundup & 165000 \\
\hline Total Pengeluaran (Rp.) & $\mathbf{7 9 6 5 0 0 0}$ \\
\hline
\end{tabular}

Adapun nilai kriteria kelayakan finansial usaha tani kopi arabika di Desa Suntenjaya, Lembang sebagai berikut:

\section{Net Present Value (NPV)}

NPV merupakan nilai sekarang dari sejumlah uang dimasa yang akan datang dan dikonversikan kemasa sekarang dengan menggunakan tingkat bunga terpilih, atau selisih antara nilai sekarang dari investasi dengan nilai sekarang dari penerimaan-penerimaan kas bersih di masa yang akan datang. Berdasarkan perhitungan dengan masa produksi 10 tahun, menggunakan tingkat suku bunga 14\% diperoleh nilai NPV Rp. 9.612.789,375,- Akumulasi nilai NPV positif mengindikasikan bahwa usaha tani kopi arabika di Desa Suntenjaya, Lembang menguntungkan dan layak dikelola.

\section{Net Benefit Cost Ratio (Net B/C)}

Perbandingan untung dan biaya dapat ditentukan sebagai perbandingan nilai keuntungan ekuivalen terhadap nilai biaya ekuivalen. Berdasarkan analisis perhitungan Net B/C Ratio diperoleh nilai Net B/C Ratio 1.98. Nilai Net B/C Ratio lebih besar dari 1 menunjukkan bahwa usaha tani kopi arabika di Desa Suntenjaya, Lembang layak dilaksanakan bila dilihat baik dari dampak sosial yang ditimbulkannya maupun dari segi finansialnya.

\section{Internal Rate of Return (IRR)}

Metode tingkat bunga pengembalian (IRR) ini digunakan untuk mencari tingkat bunga yang menyamakan nilai sekarang dari arus kas yang diharapkan di masa datang, atau penerimaan kas, dengan mengeluarkan 
investasi awal. Nilai IRR usaha tani kopi arabika di Desa Suntenjaya, Lembang dari perhitungan NPV1; DF 14\% dan nilai NPV2; DF 20\% diperoleh IRR 21.44\% dimana nilai ini lebih besar dari suku bunga bank komersial yang berlaku, yaitu $14 \%$. IRR lebih besar dari bunga bank komersial mengindikasikan bahwa usaha tani kopi arabika di Desa Suntenjaya, Lembang layak dilaksanakan.

\section{Pay Back Period (PBP)}

PBP merupakan teknik penilaian terhadap jangka waktu (periode) pengembalian investasi suatu usaha. Berdasarkan analisis perhitungan, PBP usaha tani kopi arabika di Desa Suntenjaya, Lembang 2.15 tahun atau sekitar 26 bulan. Dengan biaya investasi Rp.10.095.300,- dan umur ekonomis usaha tani kopi arabika di Desa Suntenjaya, Lembang selama 20 tahun maka proyek ini dapat dikembalikan melalui arus kas selama 2.15 tahun. Nilai 2.15 tersebut lebih pendek dari jangka waktu umur ekonomis proyek investasi, hal ini mengindikasikan bahwa usaha tani kopi arabika di Desa Suntenjaya, Lembang layak dikembangkan.

\section{Break Even Point (BEP)}

BEP merupakan suatu gambaran kondisi produksi yang harus dicapai untuk melampaui titik impas. Proyek dikatakan impas jika jumlah hasil penjualan produknya pada suatu periode tertentu sama dengan jumlah biaya yang ditanggung sehingga proyek tersebut tidak menderita kerugian, tetapi juga tidak memperoleh laba. Berdasarkan analisis perhitungan BEP diketahui bahwa titik impas untuk usaha tani kopi arabika di Desa Suntenjaya, Lembang pada penjualan senilai Rp.18.060.290 atau dapat juga dikatakan bahwa diperlukan penjualan sebesar $785.23 \mathrm{Kg}$ gabah kering kopi arabika untuk mendapatkan kondisi seimbang antara biaya dengan keuntungan.

\section{KESIMPULAN}

Hasil dari penelitian "Analisis Kelayakan Finansial Usaha Tani di Desa Suntenjaya Kecamatan Lembang Kabupaten Bandung Barat" adalah, berdasarkan hasil analisis kelayakan finansial didapat penerimaan/ pendapatan bersih sebesar Rp.4.693.625 dalam setiap hektar lahan yang dikelola, dengan tingkat suku bunga $14 \%$ diperoleh nilai NPV positif sebesar Rp. 9.104.913,375. Berdasarkan analisis perhitungan Net B/C Ratio diperoleh nilai Net B/C Ratio 2.067. Nilai IRR usaha tani kopi arabika di Desa Suntenjaya, Lembang dari perhitungan NPV1; DF 14\% dan nilai NPV2; DF 20\% diperoleh IRR $25.81 \%$ dimana nilai ini lebih besar dari suku bunga bank komersial yang berlaku, yaitu $14 \%$. Berdasarkan analisis perhitungan BEP diketahui bahwa titik impas untuk usaha tani kopi arabika di Desa Suntenjaya, Lembang pada penjualan senilai Rp.18.274.000 atau dapat juga dikatakan bahwa diperlukan penjualan sebesar $794,521 \mathrm{Kg}$ gabah kering kopi arabika untuk mendapatkan kondisi seimbang antara biaya dengan keuntungan. Berdasarkan analisis perhitungan, PBP usaha tani kopi arabika di Desa Suntenjaya, Lembang 4.11 tahun (4 tahun 1 bulan 1 minggu) atau sekitar 47 bulan. Dengan biaya investasi awal Rp.10.309.000,- dan biaya pengeluaran per hektar per tahun sebesar Rp.7.965.000, serta umur ekonomis usaha tani kopi arabika di Desa Suntenjaya Lembang selama 20 tahun maka proyek ini dapat dikembalikan melalui arus kas selama 4,11 tahun.

\section{DAFTAR PUSTAKA}

Anggraini D. 2006. Faktor-Faktor Yang Mempengaruhi Permintaan Ekspor Kopi Indonesia di Amerika Serikat, Tesis. Program Magister, Universitas 
Asosiasi Eksportir Kopi Indonesia,. 2015, Industri Kopi Indonesia, data diperoleh melalui situs internet: http://www.aekiaice.org/page/in dustri-kopi/id. Diunduh pada tanggal 5 Juli 2016.

Badan Pusat Statistik Kabupaten Bandung Barat. 2015. Kabupaten Bandung Barat dalam Angka, Bandung Barat.

Budiman, H. 2012. Prospek Tinggi Bertanam Kopi. Pustaka Baru Press: Yogyakarta.

Dinas Perkebunan Jawa Barat, (2016), Statistik Perkebunan Jawa Barat, http://disbun.jabarprov.go.id/in dex.php/. Diunduh pada 5 Juli 2016.

Direktorat Jenderal Perkebunan. 2013. Statistik Perkebunan Indonesia. Direktorat Jenderal Perkebunan Departemen Pertanian, data diperoleh melalui situs internet: http://ditjenbun.deptan.go.id/Pr oduksi_Estimasi_2013.pdf.

Diunduh pada 5 Juli 2016.

Kadariah, Karlina L, Gray C. 1999: Pengantar Evaluasi Proyek. Fakultas Ekonomi Universitas Indonesia, Jakarta.

Masri Singarimbun dan Sofian Effendi,. 1995. Metode Penelitian Survai, LP3ES, Jakarta.

Najiyati, S. dan Danarti. 2004. Kopi Budi Daya Dan Penanganan Pascapanen, Penebar Swadaya :Jakarta.

Panggabean, Edi. 2011. Buku Pintar Kopi. AgroMedia Pustaka, Jakarta.

Perum Perhutani. 2009. Keputusan Direksi Perum Perbutani Tentang Pedoman Pengelolaan Sumberdaya Hutan Bersama Masyarakat. Perum Perhutani: Jakarta.

Umar H. 1997. Studi Kelayakan Bisnis. Teknik Menganalisa Kelayakan Rencana Bisnis Secara Komprehensif. Gramedia Pustaka Utama: Jakarta. 